\#047 Leucoplasia verrugosa localizada no bordo da língua

Filipe Coimbra*, Elisabete Barbosa

Faculdade de Medicina Dentária da Universidade do Porto

Introdução: A qualquer placa branca localizada no bordo da língua, não removível por raspagem e não sendo classificada como entidade nosológica conhecida, designa-se leucoplasia. Estas placas têm potencial para evoluir para carcinoma de células escamosas devendo por isso ser eliminada cirurgicamente. As leucoplasias podem ser homogéneas ou não homogéneas; ter aspeto verrugoso ou aspeto granular, sendo estas últimas consideradas as mais perigosas. No caso dos fumadores, se desaparecerem com a cessação tabágica são classificadas como placa branca associada ao hábito tabágico e não têm potencial para malignizar. Todas as placas removidas cirurgicamente devem ser sujeitas a exame anátomo-patológico para despiste de carcinoma de células escamosas e verificar se há displasia celular. A remoção deve abarcar toda a placa para permitir um exame histológico completo.

Descrição do caso clínico: AL, masculino, 76 anos, fumador, deslocou-se à FMDUP com queixas de alteração da mucosa localizada no bordo da língua do lado esquerdo. Ao exame clínico apresentava uma placa branca, fixa, com aspeto exofítico composta por duas partes, uma de $1,5 \mathrm{~cm}$ e outra $0,5 \mathrm{~cm}$ de comprimento. O diagnóstico clínico foi leucoplasia verrugosa e foi aconselhado a deixar de fumar e fazer a remoção cirúrgica da placa seguida de exame anátomo-patológico. As placas foram removidas e suturou-se com seda 4 zeros. Passados 10 dias foi retirada a sutura e 1 mês depois avaliada a cicatrização. O exame histológico revelou mucosa do tipo lingual com aspeto acantólico, verrugoso, hiperqueratose epitelial com atipia celular mínima. Quando as placas brancas são homogéneas e associadas ao fumo de tabaco, a atitude a tomar é a cessação tabágica. Se passado 1 mês elas tiverem desaparecido, considera-se hiperqueratose associada ao tabaco e não leucoplasia verdadeira. Neste caso, como o doente estava renitente em deixar de fumar e a placa era não homogénea e verrugosa, foi classificada como leucoplasia verrugosa e feita exérese para despiste de carcinoma de células escamosas. A exérese foi total. O exame histológico revelou benignidade com caraterísticas compatíveis com leucoplasia verrugosa (acantose, hiperqueratose verruciforme e atipia celular). A atipia era mínima e a lesão cicatrizou sem evidência de recorrência. $\mathrm{O}$ doente foi aconselhado a deixar de fumar e a fazer controlos trimestrais. Se recidivar, deve ser removida novamente respeitando as margens de segurança.

http://doi.org/10.24873/j.rpemd.2018.11.285

\section{\#048 Placa Branca Localizada na Face Ventral da Língua}

CrossMark

Elisabete Barbosa*, Filipe Coimbra

Faculdade de Medicina Dentária da Universidade do Porto

Introdução: Qualquer placa branca localizada na mucosa oral que não possa associar-se a fator etiológico conhecido é classificada como leucoplasia, e como tal, tem potencial de malignização devendo ser eliminada cirurgicamente. O diagnóstico diferencial com Líquen em placas e com Candidíase hiperplásica, cuja apresentação clínica é idêntica, só pode ser feito através de exame anátomo-patológico que permitirá chegar ao diagnóstico definitivo.

Descrição do caso clínico: IMFN, feminino, 60 anos Deslocou-se à FMDUP com queixa de sensação de rugosidade na face ventral da língua. Ao exame clínico tratava-se de uma placa branca não removível por raspagem, localizada na face ventral da língua do lado esquerdo, com $1 \mathrm{~cm}$ de comprimento. Foi feita biópsia excisional com margem de segurança de $3 \mathrm{~mm}$. O diagnóstico clínico foi de leucoplasia homogénea, tendo como diagnósticos diferenciais líquen em placas e candidíase hiperplásica. O resultado do exame histológico foi hiperqueratose com paraqueratose e acantose. Estas caraterísticas interpretadas macroscopicamente são responsáveis pelo espessamento do epitélio que se traduz clinicamente por placa branca. O epitélio apresentava vacuolização celular do tipo coilocítico nas camadas superficiais fazendo suspeitar de infeção vírica. O córion tinha infiltrado linfocítico discreto e focal. A pesquisa para Cândida albicans foi negativa. Os aspetos descritos na histologia são sugestivos de leucoplasia pilosa pelo que se realizou exame imunohitoquimico que resultou negativo para o Vírus Epstein Barr descartando o diagnóstico de língua pilosa. As imagens clínicas de líquen intraoral são patognomónicas não só pelas estrias de Wickam como também pelas placas brancas localizadas na face dorsal da língua. Neste caso só se observava uma placa branca unitária sem trauma associado e sem as imagens caraterísticas do líquen plano. $\mathrm{O}$ facto de não existir infiltrado inflamatório em banda e não haver degeneração liquenoide da membrana basal reforçou a exclusão de líquen. Por outro lado, não tendo sido detetadas hifas de Cândida albicans, esta hipótese foi posta de lado. A outra hipótese que se colocava era a de leucoplasia pilosa cuja apresentação clínica era compatível, mas o facto da pesquisa ser negativa para vírus Epstein Barr não sustentou o diagnóstico clínico. O diagnóstico final, por exclusão de partes, foi leucoplasia homogénea sem displasia celular. Neste caso o tratamento consistiu na exérese cirúrgica da placa e controlo 6 em 6 meses.

http://doi.org/10.24873/j.rpemd.2018.11.286

\section{\#049 Pênfigo Vulgar, Case Report}

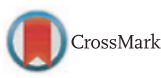

Joana Paiva*, Juliana Medeiros Almeida, Carina Ramos, Mariana Moreira, Maria João Sobreira, João Correia Pinto

Hospital de São João

Introdução: O Pênfigo vulgar é uma doença auto-imune rara, vesiculo-bolhosa, caracterizada pela formação de auto-anticorpos IgG contra as glicoproteínas desmogleína 1 e 3, induzindo dessa forma acantólise do epitélio. Geralmente afecta indivíduos na faixa etária dos 50 anos de idade e pode exibir predisposição genética. As lesões orais e cutâneas estão presentes ao mesmo tempo em $90 \%$ dos pacientes, apesar de as lesões orais precederem as de pele em $50 \%$ dos casos. Cli- 
nicamente, as bolhas rapidamente rompem deixando úlceras dolorosas com fundo necrótico e halo eritematoso. Os pacientes podem apresentar sinal de Nikolsky positivo, isto é, após fricção mecânica pode surgir uma bolha. As lesões orais podem acometer qualquer área da mucosa. O objetivo deste trabalho e relatar um caso clínico de pênfigo vulgar com manifestação oral e cutânea.

Descrição do caso clínico: Mulher de 50 anos recorre ao serviço de urgência do Hospital de São João por queixas álgicas exuberantes devido a múltiplas úlceras orais recorrentes com 1 mês de evolução, sem melhoria após antibioticoterapia, corticoterapia e terapêutica antifúngica. Ao exame objectivo apresentava múltiplas lesões orais em placa esbranquiçadas, descamativas, com eritema e raros focos hemorrágicos e algumas lesões com aspecto ulcerativo. Sem adenomegalias palpáveis. Posteriormente, ocorreu o aparecimento de bolhas na região torácica, inguinal, axilas e couro cabeludo. Apresentava também uma mancha cutânea branca na região frontal com alteração da coloração do cabelo adjacente que diz ter aparecido na idade adulta.

Discussão e conclusões: Tendo em conta o quadro clínico, suspeitou-se de uma patologia auto-imune com afecção da mucosa oral e da pele. Assim, foi proposto à doente a realização de uma biópsia oral e um estudo analítico. A biópsia veio a revelar um Pênfigo Vulgar. Iniciando desta forma terapêutica com prednisolona $60 \mathrm{mg}$ e posteriormente azatioprina $100 \mathrm{mg}$. Por ser um pênfigo refractário à terapêutica efectuada iniciou terapêutica com Rituximab 1000 mg (2 doses, separadas em 2 semanas). Mantendo-se até ao momento estável clinicamente. http://doi.org/10.24873/j.rpemd.2018.11.287

\section{\#050 Queilite Actínica: A Propósito de um Caso Clínico}

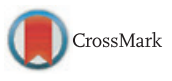

Carla Vasco*, Carolina Henriques, Orlando Lino,

Otilia Lopes, Filipe Coimbra

Faculdade de Medicina Dentária da Universidade do Porto

Introdução: A queilite actínica é uma lesão comum do lábio, induzida pela exposição crónica ou excessiva à radiação solar. Com cariz fortemente ocupacional - nomeadamente agricultores e pescadores -, atinge maioritariamente o lábio inferior, em homens caucasianos com mais de 40 anos. Normalmente de carácter crónico, pode também apresentar-se de forma aguda, esta última mais comum em jovens. A apresentação clínica pode variar entre desidratação, descamação, edema, ulceração, placas queratóticas ou erosivas/ atróficas, fissuras e perda da demarcação entre a mucosa labial e a porção cutânea do lábio. Histologicamente pode verificar-se, na mucosa, hiperplasia ou atrofia epitelial, com ou sem displasia, e hiperqueratose; e, no tecido conjuntivo, inflamação, vasodilatação e elastose solar. A queilite actínica é uma patologia potencialmente maligna, pelo que são de extrema importância o diagnóstico precoce e tratamento e seguimento adequados.

Descrição do caso clínico: Mulher, 92 anos, caucasiana. Profissão: agricultora. Sem antecedentes clínicos e/ou cirúrgicos relevantes. Apresenta-se à consulta por 'ferida no lá- bio" (sic), com evolução inferior a 6 meses, assintomática e com sangramento esporádico. Ao exame objetivo observa-se lesão ulcerada no lábio inferior à direita, na transição mucosa/epiderme, com áreas de encrustação. Mais tarde, apareceu lesão idêntica no lado oposto do lábio. Realizou-se biópsia incisional e o estudo anatomopatológico confirmou o diagnóstico de queilite actínica com displasia moderada. Foi indicada a aplicação tópica de diclofenac sódico 3\% (Solaraze ${ }^{\circledR}$ ) e creme reparador (Cicalfate ${ }^{\circledR}$ ) e cuidados de proteção solar. Ao fim de 10 semanas verificou-se remissão total das lesões no lábio.

Discussão e conclusões: Estima-se que 95\% dos carcinomas espinocelulares do lábio tenham sido precedidos por uma queilite actínica. A biópsia assume um papel importante, permitindo fazer diagnóstico diferencial, assim como perspectivar o prognóstico e o tratamento da patologia. $\mathrm{O}$ tratamento pode ser cirúrgico (vermelhonectomia) - bisturí frio, laser, criocirurgia - ou não cirúrgico - aplicação tópica de compostos como o 5-fluorouracilo ou o diclofenac, entre outros, bem como a fotoproteção e terapias fotodinâmicas. Não há, ainda, consenso relativamente à melhor estratégia terapêutica, sendo necessários mais estudos. Em qualquer circunstância, é importante o acompanhamento periódico do paciente, a fim de evitar recidivas e dimiuir o risco de malignização.

http://doi.org/10.24873/j.rpemd.2018.11.288

\section{\#051 Cimentoblastoma - apresentação de caso clínico}

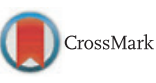

Patrícia Caixeirinho*, Marcelo Prates, Céu Machado, Ana Fernandes

Hospital de São José; Hospital de Dona Estefania

Introdução: O cimentoblastoma, descrito pela primeira vez em 1927 por Dewey, é um tumor odontogénico dos cimentoblastos, caracterizado pela proliferação de uma massa semelhante a cimento em continuidade com a raíz do dente envolvido. Trata-se de uma entidade rara e benigna, que representa menos de $1 \%$ de todos os tumores odontogênicos; $75 \%$ dos casos surgem na mandíbula e $90 \%$ nas regiões pré-molar e molar. O cimentoblastoma ocorre mais frequentemente entre a segunda e terceira décadas de vida. Os dentes decíduos raramente são afetados. Cerca de dois terços dos doentes tem dor e aumento de volume. Radiograficamente, observa-se uma massa radiopaca fundida a um ou mais dentes e circundada por um fino halo radiotransparente.

Descrição do caso clínico: Homem de 31 anos, raça negra, sem antecedentes pessoais relevantes, foi observado na consulta de Cirurgia Oral do Serviço de Estomatologia do Hospital de São José por odontalgia no dente 46 endodonciado. A dor tinha carácter espontâneo, com agravamento no último mês à mastigação. Na radiografia peri-apical observou-se lesão radiopaca de limites definidos, estendendo-se da raíz distal de 46 à raíz mesial de 47, circundada por um halo radiotransparente. A biópsia incisional foi inconclusiva. Foi feita extração de 46 e excisão da lesão; a histopatologia confirmou o diag- 